\title{
Da dispersão à concentração e o caminho de volta: uma análise da política entre os Waiwai
}

\author{
Victor Alcantara e Silva*
}

\begin{abstract}
Resumo: 0 grupo a que se denomina Waiwai é hoje composto por diversos povos que habitavam de forma dispersa uma extensa área do escudo das Guianas. Atraídos pelas promessas do xamã Ewká, de uma vida pacífica e generosa, empenharam um processo de aglomeração que alterou o padrão de assentamento regional, tornando as aldeias maiores e mais sedentárias. Nesse trabalho procuro explorar o aspecto profético da pregação de Ewká e, utilizando como reflexão trabalhos sobre o profetismo Guarani, compreender o sentido da perambulação Waiwai.
\end{abstract}

Palavras-chave: etnologia, política, profetismo, Waiwai.

\section{Introdução}

Este texto retoma parte dos caminhos percorridos nos dois anos em que me dediquei a estudar a etnografia Waiwai, no trabalho que desenvolvi na monografia de graduação. 0 interesse pela antropologia política me levou aos estudos sobre os índios Guarani, que me influenciaram na interpretação do caso dos Waiwai, principalmente em razão de certo profetismo desenvolvido por um de seus chefes a partir do contato com os missionários. Além disso, esse percurso foi marcado pela curiosidade que desenvolvi na graduação pelo problema da transformação, quando não do desaparecimento, das sociedades indígenas a partir do "contato".

$\mathrm{Na}$ antropologia, durante certo período, àqueles que escapassem do extermínio físico, restava o desaparecimento cultural. Nos estudos de "aculturação", os índios, colocados passivamente como objetos de corrupção de sua própria cultura por aquela supostamente dominante, seriam invariavelmente tragados no decorrer da história. No entanto, dentre aqueles povos que não desapareceram de fato, vemos que eles não se dissolveram na sociedade nacional, e permaneceram afirmando sua diferença. Em um movimento mais recente, a etnologia visou positivar as relações de contato ao tratá-las da perspectiva nativa, elaborando "cosmologias de contato" (RAmos; Albert, 2000). Desse ponto de vista, em vez de serem os índios uma ques-

\footnotetext{
* Graduado em Ciências Sociais - UFMG.
} 
tão para o Estado, o próprio Estado e os brancos se tornam um problema para os índios, que, assim, se tornam protagonistas na história. No entanto, parece-me que alguns desses estudos, ao se focarem demasiado nas permanências, atenuam a ação da história sobre os ameríndios.

Observando os povos nativos atualmente, fica claro que suas condições de vida mudaram. Ainda que preservem sua distintividade, as sociedades indígenas se transformaram para se acomodar em um sistema em que não mais as relações entre povos livres é a realidade, mas em que todos estão, em alguma medida, ligados ao poder regulador do Estado. Acredito que para abordar a questão da mudança é necessário, primeiro, admitir que aquelas sociedades "selvagens" - no sentido clastreano de serem livres - de fato desapareceram. Isso não significa que foram aculturados, ou que deixaram de ser índios, mas que, em um mundo que mudou, tiveram que apreender novos conhecimentos e travar novas relações, e assim produzir modificações orientadas por uma filosofia própria.

Apresento brevemente alguns pontos a respeito dos índios Guarani a fim de refletirmos sobre essa questão, antes de passar aos Waiwai.

\section{Ensinamentos Guarani}

O estudo a respeito da mudança entre os guarani é abundante. No clássico livro de Hélène Clastres, Terra Sem Mal, a autora revisa algumas dessas teorias a fim de entender a mensagem religiosa desses índios, pois duvida que a religiosidade guarani seja tributária da experiência vivida nas missões do Chaco. A autora se volta então para o aspecto profético da religião guarani em torno dos mitos que tratam da Terra sem Mal. Hélène Clastres aposta que, se no passado o discurso dos karaí, os profetas, apontava para a possibilidade concreta da Terra sem Mal através das migrações, depois do contato e encapsulamento territorial desses grupos por parte do Estado - o que os impede de desenvolver suas vidas de acordo com os ideais tradicionais - a religião profética teria passado a anunciar o fim da existência guarani.

Os antigos profetas, ao percorrerem as aldeias, reuniam-se com os homens, que dançavam e cantavam em seu entorno, enquanto o karaí discursava, anunciando o fim próximo da terra, articulando-o com o mito do dilúvio que acabou com a primeira terra; lembrava aos homens as guerras e instigava a vingança; prometia a todos o acesso à Terra sem Mal, onde a flecha busca a caça sozinha e a mandioca 
dá por si só, onde pode-se casar as filhas com qualquer um, onde vive-se em festa e é-se imortal. Assim reuniam milhares em grandes migrações que teriam por objetivo sua busca. A autora enfatiza o caráter de ascese da própria viagem: a migração é a realização do discurso do karaí , é o abandono das práticas sociais, é a tentativa dos homens viverem livres de coerção, tal como os deuses. Dessa forma, a própria lógica da migração profética determina seu fracasso: é impossível viver, como humano, fora das regras da sociedade.

Essa não seria mais a realidade atual dos Guarani, que teriam deslocado o sentido de sua religião, uma vez transformada sua sociedade pelas condições impostas pela dominação pelos brancos. Antes livres, os Guarani agora estariam conscientes de seu fim. Dessa forma, a religião teria se tornado local de afirmação de diferença em relação aos brancos, ao mesmo tempo em que a Terra sem Mal se deslocou da concretude para o plano metafísico, uma vez que as migrações se tornaram impossíveis. Existir como Guarani, atualmente, é experimentar uma condição ambígua, pois ao mesmo tempo em que são depositários dos deuses e devem seguir as regras sociais enviadas por eles a fim de atingir sua morada, seria preciso negá-las para se igualar às divindades. Assim, a sociedade e os laços que a constituem apareceriam, hoje, como meio para a imortalidade. Dessa maneira, os antigos guaranis negariam radicalmente a sociedade, enquanto os atuais a validariam como meio de conquistar a imortalidade.

No entanto, apontam Eduardo Viveiros de Castro e Manuela Carneiro da Cunha (CARNEIRo DA CUnHA, 2009) que os dois únicos aspectos não negados pelos antigos karaí, a vingança e o canibalismo, eram justamente o fundamento da sociedade tupi-guarani, e o meio através do qual o guerreiro atingia a imortalidade. Penso, assim, que tanto no passado quanto agora, a busca pela imortalidade passaria ao mesmo tempo por negar certos valores enquanto se busca efetivar outros, que são o cerne da sociedade. Como nota Renato Sztutman (2009), essa "consciência do fim", que Hélène Clastres identifica, arrasta-se pelo tempo sem que os Guarani de fato tenham desaparecido.

As migrações e deslocamentos poderiam então ser vistos como forma de ajustamento do plano da socialidade visando às condições que possibilitem que um desejo coletivo, que os antigos karaí sabiam expressar, efetue-se aqui e agora, baseadas em um fundo metafísico ligado à imortalidade. Assim, as migrações poderiam ser vistas como fruto de motivações múltiplas, não apenas de caráter religioso. 
Retomarei mais a frente o assunto, depois de termos passado pelo caso dos Waiwai, a fim de extrair algumas considerações dessa apresentação dos Guarani. Aponto agora apenas que me parece que a separação rígida entre interior e exterior da "cultura" no estudo de Hélène Clastres faz com que toda mudança, sendo externa ao universo indígena, torne-se negativa e corruptora, degenerando de um suposto modo de vida tradicional. Dessa perspectiva, mudar parece necessariamente iniciar um processo de destruição, e nesse caso o destino dos índios seria, de fato, desaparecer.

\section{Um profetismo Waiwai?}

Essa questão é importante quando olhamos hoje para os povos indígenas. Os historiadores já mostraram que mesmo aqueles mais remotos grupos, os "isolados", estão ligados aos acontecimentos históricos da invasão europeia, problematizando a ideia de um modo "tradicional" de vida associado ao quadro observado etnograficamente.

O caso dos Waiwai permite que acompanhemos parte dessas mudanças na História. Esse grupo é hoje formado por diversos povos que habitavam de forma dispersa uma área extensa próxima à Serra do Acarí, que divide Brasil e Guianas, como os Xereu, Katuena, Mawayana, dentre outros. A partir da década de 1960, quando missionários norte-americanos se estabelecem permanentemente na região, ocorre uma brusca alteração nas relações indígenas e no padrão de assentamento regional. A partir de sua instalação próxima a uma dessas aldeias, cujos habitantes os guias Wapixana que os acompanhavam denominavam Waiwai, e a conversão de um prestigioso xamã regional, chamado Ewká, têm início expedições de busca a fim de atrair mais pessoas para a base da missão na então Guiana Inglesa.

Essas expedições, das quais Ewká e outros índios tomavam parte, lograram atrair vários grupos para o arredor da aldeia do ex-xamã, que aos poucos se tornou um chefe geral nesse novo contexto, em que os diferentes grupos, às vezes antigos inimigos, passavam a compartilhar um mesmo espaço comunitário. Essa nova configuração contrasta com o padrão tradicional consagrado na etnografia, de pequenas aldeias autônomas e dispersas entre si (cf. RIVIÈRE, 2001).

No ano de 2011, passei cerca de 20 dias em uma aldeia Waiwai, chamada Takara, na margem direita do baixo rio Mapuera, afluente do Trombetas. Havia dois homens bastante velhos na aldeia, Wihxo e Wiku, ambos com cerca de 90 anos de 
idade, com os quais pude conversar. Assim fiquei sabendo que a antiga aldeia de Wihxo foi visitada por uma dessas expedições. Segundo seu filho, Asadó, quando Ewká chegou com os missionários, Wihxo desconfiou de suas intenções e não seguiu com eles para a missão (cf. DiAs JR., 2006, p. 46). No entanto, Asadó foi com a expedição, e algum tempo depois toda a aldeia seguiu para lá. Segundo me contou o velho, essa expedição deixou com eles apenas um terçado, com a promessa de que receberiam mais na missão. Sua aldeia foi contactada nas cabeceiras do rio Mapuera, onde haviam se estabelecido próximo aos índios Parukoto depois de uma série de migrações, após seu pai ter sido morto em uma aldeia no rio Cachorro. Wihxo disse que nessa época havia muita briga entre e dentro das próprias aldeias, que se cindiam.

Ambos disseram que, à medida que iam chegando novos moradores à missão, Ewká lhes falava longamente: dizia o ex-xamã que conhecia a vida deles e que deviam abandonar toda a feitiçaria, as bebidas fermentadas, o xamanismo e ficar somente com Deus. Obviamente isso não era prontamente aceito. 0 pessoal de Wihxo realizou festas escondidas durante algum tempo, até que a pressão dos missionários os fez parar de vez, para sua infelicidade. Do grupo de Wiku, algumas pessoas daquelas aldeias contactadas retornaram ao Cachorro após se abastecerem com os missionários. Anos depois, quando os parentes da missão resolveram visitá-los, se depararam com uma população dispersa, doente e reduzida pelas brigas. Resolvem todos então seguir novamente para a missão, onde se instalaram.

A narrativa dos velhos vai ao encontro daquelas consagradas na literatura sobre os Waiwai, que apontam o discurso de Ewká carregado de promessas de uma vida generosa e em paz para aqueles que vivessem próximos à missão, onde as guerras e o rapto de mulheres não teria lugar. A construção dessa forma de organização exigiu uma série de alterações em relação à forma de vida que levavam antes. Como se vê, ela passa inicialmente pela promessa de uma boa vida, pacífica e generosa, e pelo controle de alguns elementos tradicionais. Paralelamente à transformação das relações com suas entidades, há um rearranjo da política aldeã que possibilita, ao mesmo tempo em que cria, o contexto aglomerado: uma identidade genérica Waiwai foi sendo criada a partir da alfabetização e compartilhamento de valores, as aldeias passaram a se organizar em casas familiares dispostas em "bairros", a chefia, antes ligada ao xamã, foi desdobrada em várias figuras, principalmente o cacique e pastor, que foram distribuídas entre os núcleos familiares que passaram a formar as aldeias. 
Foi com essa imagem de transformações que fui a campo e escutei Wihxo e Wiku. De certa maneira, suas falas corresponderam ao que eu havia absorvido das leituras, mas também apontaram outros aspectos: ao tentar saber de Wihxo a diferença da vida antes e depois da aglomeração, ele me respondeu simplesmente que era "nenhuma", e que continuavam vivendo como antes, resposta que me deixou confuso. Posteriormente, relembrando suas palavras, percebi que a referência a algumas mudanças negativas vividas por ele, como o fim das festas tradicionais, o abandono dos adornos e a adoção de roupas, a alteração da relação entre as aldeias, convivem com outras positivas, como a satisfação com a aldeia em que reside. Explico: Wihxo, se referindo à época da morte de seu pai, seguida pela fuga e migração pelo Mapuera, disse ser aquela uma vida muito dura, e que, sem as ferramentas de ferro, era muito difícil abrir as roças. Apontando para os arredores de Takara, disse satisfeito que hoje em dia as roças são grandes e que há muita fartura.

Apesar das mudanças reconhecidas, ele considera que não há diferença entre a vida antes e depois da evangelização e aglomeração. Dessa forma, penso que houve a manutenção daquilo que Joanna Overing (2002) definiu como um "senso de comunidade" nativo entre os Waiwai. Apesar de ocorrerem transformações na morfologia social e política, na relação com os espíritos, na escatologia e etiologia, além ainda de diversos implementos técnicos, os princípios morais e filosóficos - ou cosmológicos -, que regem a socialidade, aparentemente não foram substituídos.

Se antentarmos para a história da região, podemos compreender melhor a conversão e a aglomeração iniciada a partir do contato com os missionários. A fala de Wihxo parece apontar para um traço fundamental da dinâmica política indígena, em que o constante deslocamento permite a aquisição de certos conhecimentos que possibilitam a realização de um ideal de vida, que nas Guianas está ligado à valorização da autonomia. Como Overing (1991) argumentou, para entendermos a organização social e política indígena, seria preciso levarmos a sério sua concepção do que é o "social", que, nas Guianas, estaria ligado à ideia de que o socius é meio de se evitar relações de dominação.

No caso dos Waiwai, Catherine Howard (2002) indica que o sentimento que deve prevalecer na aldeia é aquele Tawake, de convivialidade ou pacificidade, produzido pela convivência harmônica e pelo fluxo das trocas sociais, da generosidade e da troca recíproca, o que se atinge entre parentes. As festas, por exemplo, são vistas como momentos em que esse sentimento é revitalizado através do estado gene- 
ralizado de reciprocidade e o espaço da aldeia é local em que um chefe é responsável por guiar os sentimentos coletivos, resolver conflitos, motivar os trabalhos, constituir a paz na comunidade. 0 comportamento solitário e agressivo é constantemente desencorajado, pois é típico das relações travadas com estrangeiros e associado ao exterior da socialidade Waiwai.

Nas conversas com os velhos, as constantes referências às brigas corroboram a descrição de viajantes e etnógrafos que percorreram a região antes do início da conversão. Os relatos de epidemias e de guerras são constantes, bem como o de extermínio de aldeias inteiras. Ruben Caixeta de Queiroz (1999) aponta que a doença entre os Waiwai era interpretada na lógica xamânica, e assim desencadeava ciclos de vingança, uma vez que tinham intenção humana. De fato, em campo, não ouvi dos velhos relatos de doenças em tempos antigos, apenas de morte por "sopro", pauladas ou flechadas, decorrente de brigas. A doença, assim, engendrava um tipo de guerra que, por sua escala, escapava à lógica da reciprocidade canibal, que parece ter sido outrora a realidade na região, e causava certa perversão nas relações nativas (Dreyfus, 1993). Ainda Caixeta de Queiroz defende que as transformações iniciadas com a missão guardam relação com o passado, pois seriam o aprofundamento de estratégias de sobrevivência que já estavam em curso, como a migração pelo território buscando tanto o afastamento dos inimigos, mas também a aproximação e fusão com grupos aliados.

Tendo esse quadro em mente, podemos avaliar melhor as mudanças que os Waiwai produziram. Após a chegada dos missionários, em torno dos quais havia tanto apreensão quanto interesse, Ewká se torna figura central, uma vez que, escolhido pelos norte-americanos por ser um chefe em ascensão, passa a ter relação privilegiada com eles. Assim, penso que, devido ao prestígio adquirido nesse processo, que em grande medida escapa ao seu controle, Ewká se tornou momentaneamente capaz de rearticular antigas redes (ao mesmo tempo em que criou novas) que uniam esses diversos grupos.

Seu discurso indica as transformações necessárias para que o aglomerado possa se formar, pois se refere principalmente à supressão do conflito, causador de dispersão, através do controle da feitiçaria e das festas de bebida. No quadro de depopulação e doenças enfrentado pelos indígenas na primeira metade do século $\mathrm{XX}$, a missão parece ter sido um meio eficaz de refrear esse processo. A etnografia contém referências à intensa perambulação do ex-xamã por aldeias diversas a fim 
de atrair os índios, sob a promessa de uma vida melhor. Esse aspecto algo profético de Ewká talvez não seja fortuito, pois pode ter encontrado respaldo no anseio dos índios em por fim a uma situação negativa. Howard aponta ainda que, paralelamente às promessas de Ewká, havia a ênfase escatológica da pregação evangélica, o que teria disseminado a apreensão do fim do mundo na região.

Dessa maneira, a fala de Wihxo aponta para questões importantes: primeiro, que aquele quadro de ocupação tido como "tradicional", de aldeias pequenas e impermanentes, pelo menos no caso dos Waiwai, deve ser tomado como um momento específico de sua história, ligado a um período negativo, de constantes conflitos e fugas. Segundo, que a migração aparece como forma de novamente dar curso a um ideal de vida, ou ajustar as relações sociais com vistas a efetivar certos desejos.

\section{Nota final: o movimento como política}

Resta ainda a questão de saber por que esses grupos de certa forma abriram mão de sua liberdade para se juntar aos Waiwai e aos missionários, que, como vimos, os pressionavam para alterar certos costumes. Howard aponta, inclusive, que os Waiwai constituiam relações assimétricas com os grupos atraídos devido ao acesso privilegiado aos missionários. Enfatizando o processo de "waiwaização", isto é, de transformação dos antigos grupos em Waiwai através tanto do controle político, quanto da educação moral e das trocas matrimoniais, a autora parece construir uma imagem em que a diferença e o perigo da convivência entre os diferentes povos se atenuou. De fato, parece haver uma ênfase nativa nessa atenuação, pois é sabida da tendência ao mascaramento da afinidade no interior das aldeias guianenses devido ao perigo representado pelo exterior.

Porém, se no momento de sua pesquisa os Waiwai enfatizavam a unidade, agora, que passam por um processo intenso de dispersão, a diferença é constantemente explicitada, ligada aos antigos grupos atraídos e a seus respectivos lugares de origem. Dessa forma, é possível perceber que, paralelamente à “waiwaização", houve e há a produção de diferença no interior do aglomerado. Os antigos grupos se perpetuam nas aldeias, ligados a um passado e origem comuns, e reafirmam essa diferença em diversos momentos. A forma de organização dos "bairros" seguiu os mesmos princípios das antigas casas coletivas, gerando disputa política no interior da aldeia. Segundo Howard, nesses conflitos, não raro o grupo politicamente proeminente repreendia aqueles incorporados mais recentemente, referindo seu comportamento 
ao fato de não serem waiwai, reforçando o ideal de sua centralidade política e reavivando os princípios que fundamentam o pertencimento a sua "ordem".

Como foi possível perceber em campo, essa ordem, no entanto, não é permanente: tão logo os outros grupos são incorporados, assumem diferentes posições. Assim, se há a assimetria, ela não fixa as posições. E nos conflitos que surgem, o pertencimento à ordem Waiwai é antes evocada como um compartilhamento de valores do que ligada a privilégios de um grupo específico e garantidos hereditariamente. Assim, julgo que se no passado esses diversos grupos buscaram a missão como forma de satisfazer um anseio pelo fim dos conflitos generalizados, o acesso aos remédios e bens ocidentais, isso não significou se subordinar a um sistema de dominação política. Pelo contrário, parece-me que a busca por relações diretas com os missionários tinha como motivação não depender da mediação de outros grupos pelo acesso aos bens e recursos desejados, o que, atualmente, efetivou-se.

E que podemos concluir? Acredito que podemos pensar no profetismo não apenas como um momento, mas como uma via do pensamento, que no caso dos Waiwai possibilitou que naquele contexto específico eles dessem curso ao processo de aprendizado e incorporação do exterior de elementos que julgaram importantes. Incorporação essa que no caso desses índios parece ser mais da domesticação que da predação. Retomando mais uma vez Sztutman (2009), não é também político o sentido da busca da Terra sem Mal? Isto é, ela não aponta para um adequamento das relações terrenas tendo em vista um ideal - ainda que ele baseie-se no pós-morte? ${ }^{1}$ Dessa maneira, podemos pensar que o longo caminho percorrido pelos grupos que compõem os Waiwai tem a ver com o ajustamento de um ideal de vida, que, nas Guianas, sabemos estar ligado à valorização da autonomia.

Em pouco mais de 60 anos, os Waiwai aprenderam muito com suas perambulações: as grandes canoas de tronco, aprendidas com os Wapixana, que possibilitaram a circulação por áreas distantes em busca de isolados; aprenderam, aos poucos, a serem índios enquanto categoria jurídica, ao passo que lidavam com órgãos federais e os missionários, e assim a garantir direitos perante o Estado; passaram a lidar

\footnotetext{
${ }^{1}$ Também entre os Waiwai o destino pós-vida atual implica em atingir um lugar em que "everyone is decked in their most 'beautiful' bead and feather finery all the time and engaged in perpetual feasting, dancing and laughter. Each soul obtains a new spouse. No one has to work; nothing ever decays and food and wealth items just appear on their own. No one ages and no one can die; weapons would just pass through their diaphanous spirit-bodies" (HowARD apud Caixeta de Queiroz, 1999, p. 278).
} 
com o dinheiro e com isso a depender menos da mediação dos missionários e órgãos públicos para o acesso aos bens; introduziram a escola, pois assim podem entender melhor os brancos e formar seus próprios profissionais; aprenderam português, inglês, francês, e assim perambulam eles mesmos pelas cidades do Brasil, Suriname, Guiana; produziram, com base na relação entre os $Y a n a^{2}$ e deles com os brancos, um tipo de conduta pacífica que permite que as aldeias se tornem locais de reunião de objetos e relações que julgam produzir felicidade.

O movimento que vemos hoje, de dispersão, carrega toda essa incorporação. As novas aldeias, ainda que pequenas e sociologicamente próximas daquelas do passado, não serão mais como estas. No passado, o discurso algo profético de Ewká encontrou expectativa entre aqueles que viviam perambulando pelas Guianas, ajuntando-os. E, depois do longo tempo vivendo não apenas com, mas como Waiwai, que possibilitou a aquisição do conhecimento necessário à produção de uma existência autônoma nesse novo mundo em que foram inseridos, talvez seja a hora de voltar para casa e exercê-lo em suas próprias comunidades, em um novo ciclo de dispersões e associações.

\section{Referências}

CAIXETA DE Queiroz, R. (1999). “A saga de Ewká: epidemias e evangelização entre os Waiwai”. In: Wright, R. (Org.). Transformando os deuses: os múltiplos sentidos da conversão entre os povos indígenas no Brasil. Campinas, Ed. Unicamp.

Clastres, H. (1978). Terra sem Mal. São Paulo: Editora Brasiliense.

DiAS JR., C. M. (2006). Entrelinhas de uma rede. Entre linhas Waiwai. Tese de Doutorado. São Paulo, USP.

DREYFUS, S. (1993). “Os empreendimentos coloniais e os espaços políticos indígenas no interior da Guiana Ocidental de 1613 a 1796". In: Viveiros de Castro, E.; CARNEIRo DA Cunha, M. (Org.). Amazônia: etnologia e história indígena. São Paulo, NHII/USP/ FAPESP, p. 19-41.

HowARD, C. (2002). Wrought identities: the Waiwai expeditions in search of the "unseen tribes" of northern Amazonia. Tese de Doutorado. Chicago/Illinois, The University of Chicago.

\footnotetext{
${ }^{2}$ Sufixo que identifica alguma "gente", geralmente a partir do local de habitação, por exemplo Kahyana, Kaxuyana, Mawayana, Tunayana, Tikyana, etc.
} 
OvERING, J. (1991). "A estética da produção e o senso de comunidade entre os Cubeo e os Piaroa". Revista de Antropologia, n. 34. São Paulo, USP.

. (2002). "Estruturas elementares da reciprocidade". Cadernos de Campo, n. 10, ano 11. São Paulo, PPGAS/USP.

Ramos, A.; Albert, B. (Org.). (2000). Pacificando o branco: cosmologias do contato no Norte-Amazônico. São Paulo, Ed. UNESP.

Rivière, P. (2001). Indivíduo e sociedade na Guiana: um estudo comparativo da organização social ameríndia. São Paulo, Edusp.

Sztutman, R. (2009). "Religião nômade ou germe do Estado? Pierre e Hélène Clastres e a vertigem Tupi". São Paulo, Novos Estudos - CEBRAP, n. 83.

Recebido em dezembro/2012

Aprovado em fevereiro/2013 